\title{
Could STEM-based Phenomenon Learning Improve Students' Proportional Reasoning?
}

\author{
Ahmad Suryadi, Lia Yuliati*, Hari Wisodo \\ Department of Physics, Faculty of Mathematics and Sciences, Universitas Negeri Malang, Jl. \\ Semarang No. 5 Malang, 65145, Indonesia \\ Email: lia.yuliati.fmipa@um.ac.id
}

\begin{abstract}
This study investigated the influence of Science, Technology, Engineering, and Mathematics (STEM) based phenomenon learning on students' proportional reasoning. The embedded mixed method design was utilized with 25 senior high school students in the East Java Province, Indonesia at the 2019/2020 school year. The data were collected via written tests (pretest and posttest) and interviews to find the effect of STEM-based phenomenon learning on students' proportional reasoning. Data were analyzed with the Wilcoxon signed-rank test and categorized into five levels of proportional reasoning. The result showed that STEM-based phenomenon learning led to no statistically significant increase in the students' proportional level. There was also a slight decrease in the percentage of students who categorized as level 4 (ration). In particular, the qualitative analysis documented that the students only focus on the proportion of one variable that changes and does not pay attention to changes in other variables. The students also indicated to provide an inverse proportion.
\end{abstract}

Keywords: proportional reasoning; STEM; Phenomenon-based Learning; heat

\section{Introduction}

In recent years, proportional reasoning has received much attention in science education research. Although proportional reasoning is fundamentally closer to the study of mathematics [1], proportional reasoning is also important in the fields of science including physics [2]. Physics characteristics that are quite mathematical make proportional reasoning can help students in learning. By proportional reasoning, a science concept could be connected to a mathematics concept [3]. It is an essential unit to understand physics concepts [4],[5]. In addition, according to Akatugba and Wallace [6] study, proportional reasoning not only related to the science concept understanding but also related to problem-solving in cultural, social, cognitive, and contextual elements in learning physics. However, many students still difficult to understand ratio and proportion in science concepts [7].

There have been several attempts to empower students' proportional reasoning. Bentley \& Yates [8] found that in mathematics, working examples can help students to improve their proportional reasoning. Another finding from Dubovi et al. [9] study, they found that Simulation-Based Learning Environment could assist nursing students in increasing proportional reasoning. Erlina et al. [10] used evidence-based reasoning to improve students' scientific reasoning in general. Those results implied that reasoning is the result of a learning process [11]. However, some studies found the opposite where reasoning is a mental process that is not influenced by learning factors. One of the examples is Ding et al. [12] study who concluded that majors, years, and types of institutions did not make a difference in the participants' reasoning skills. There was still no consensus about those views. Therefore, this current research was conducted to fill the conundrums in reasoning specifically on proportional reasoning aspects. 
In this era, many countries concerned to graduate more Science, Technology, Engineering, and Mathematics (STEM) alumni. Hence, the learning process in secondary schools applied the STEM approach. STEM education is an interdisciplinary approach to integrating science, technology, engineering, and mathematics [13]. There are several STEM learning innovations that have been carried out by scientists in improving student competencies. Lou et al. [14] found that learning models in STEM with problem-based learning (PBL) had a positive effect on students' attitudes in terms of both cognitive and attitude. While Kim et al. [15] found that computer-based scaffolding in STEM-PBL can have a significant influence on student learning outcomes. Survey research conducted by Tseng et al. [16] found that STEM combined with project-based learning was effective in improving student attitudes. Research by Yuliati et al. [17] also found that STEM learning with inquiry-based learning had a significant effect on students' mastery of concepts and scientific literacy. The results of this study indicate that STEM learning could be combined with another instructional method to improve students' capabilities.

STEM learning combined with phenomenon-based learning is the potential to implement in science education. Phenomenon based learning is holistic [18], while STEM is also an integration of four different disciplines. Through phenomena, students not only observe but can also think of various possibilities that can later be designed and tested (deductive reasoning) [19]. In addition, the engineering design process in STEM learning provided a chance to drill students' proportional reasoning. This study seeks to combine STEM learning with phenomenon-based learning in heat and temperature topics. This study aims to determine whether STEMbased phenomenon learning influences student proportional reasoning.

\section{Method}

This study is a part of a mixed-method project on exploring students' scientific reasoning skills through STEM-based phenomenon learning. The study used an embedded experimental mixed-method design. Embedded experimental is one of the mixed-method research designs where quantitative and qualitative data integrated to enhance the result [20]. The study began with qualitative research to reveal the students' difficulties and instructional barriers. Based on the result of the qualitative investigation, the instructional intervention implemented in heat and temperature topics. Students conducted a written test before and after instruction (pretest and posttest). After the intervention, some students were interviewed in Bahasa. All the data were analyzed quantitatively and qualitatively.

The participant in this study was 25 senior high school students at 11 grade when they learned the heat and temperature topic. There was only one class participated in this study. Despite the generalization of the study was poor, limited participant provided a chance for the researcher to explore the students' proportional reasoning deeply. STEM-based phenomenon learning was implemented in this study. STEM-based phenomenon learning is an instructional design combining the Science, Technology, Engineering, and Mathematics (STEM) approach and phenomenon-based learning (PhenoBl).

There were four classroom meetings on this topic. The first meeting is about temperature and expansion. The second meeting is about the heat. The third meeting is about the Blacks' Principle. The last meeting is about the heat transfer mechanism. All meetings provided a real phenomenon that students have experienced, inasmuch as the use of rivets, the process of mixing ice and coffee, the melting phenomena in polar areas. In addition, the process of students' learning was shaped by the STEM approach.

The instrument used in this study was two numbers of scientific reasoning essay test with reliability 0.5 . The first problem is about the heat capacity concept, and the second problem is about the Blacks' Principle. The questions present in Figure 1.

Analyzing the data was done by using a nonparametric test. The nonparametric test, Wilcoxon-signed rank test, was used to compare the pretest and the posttest result statistically. Besides, proportional reasoning data also categorized into five levels. The categorization rubric was adapted from Karplus [21]. The Rubric presents in Table I. 


\section{The First Problem}

Object $\mathrm{X}$ and object $\mathrm{Y}$ are two different metals. If object $\mathrm{X}$ requires $1,500 \mathrm{~J}$ heat so the temperature rises from $40^{\circ} \mathrm{C}$ to $50^{\circ} \mathrm{C}$. What is the heat required to increase the temperature of object $\mathrm{Y}$ from $20^{\circ} \mathrm{C}$ to $25^{\circ} \mathrm{C}$ if the heat capacity of object $\mathrm{X}$ is twice the heat capacity of object Y?

\section{The Second Problem}

In the results of the analysis of an experiment, the results showed that a calorimeter with a current of 2 A with a voltage of 10 volts for 2 minutes, the water in the calorimeter absorbed heat worth 2,400 J. How much voltage must be made so that the water in the calorimeter absorbed heat of 3,600 J, if fixed circuit installed with the same current and time?

Fig. 1: Proportional Reasoning Problems

TABLE I: Rubric of Proportional Reasoning

\begin{tabular}{cll}
\hline \hline Level & \multicolumn{1}{c}{ Category } & \multicolumn{1}{c}{ Description } \\
\hline 0 & No answer & Does not provide answers/explanations/reasons \\
1 & Intuitive (I) & Guess answers, use numbers or settlement strategies randomly (carelessly) and answers are not logical \\
2 & Adaptive (A) & Use a settlement strategy but focus on different things \\
3 & Transitional (Tr) & Implement and use an equation strategy with a ratio and determine the value but it is not right \\
4 & Ration (R) & Apply and use an equation strategy with ratios and determine values precisely \\
\hline \hline
\end{tabular}

\section{Results}

The descriptive statistics of students' proportional reasoning pretest, posttest, and Wilcoxon signed-rank test presents in Table II.

TABLE II: Median and Wilcoxon Signed-rank test result of Students' Proportional Reasoning

\begin{tabular}{lllllll}
\hline \hline \multicolumn{1}{c}{ Time } & & $\mathrm{N}$ & & Median & $\mathrm{z}$ & $\mathrm{P}$ \\
\hline Pretest & 25 & & 75 & & -1.115 & 0.909 \\
Posttest & 25 & & 75 & & & \\
\hline \hline
\end{tabular}

The Wilcoxon signed-rank test revealed that there was no statistically significant increase in students' proportional reasoning level after the students completed the STEM-based phenomenon learning, $\mathrm{z}=-1.115$, $\mathrm{p}>.05$.

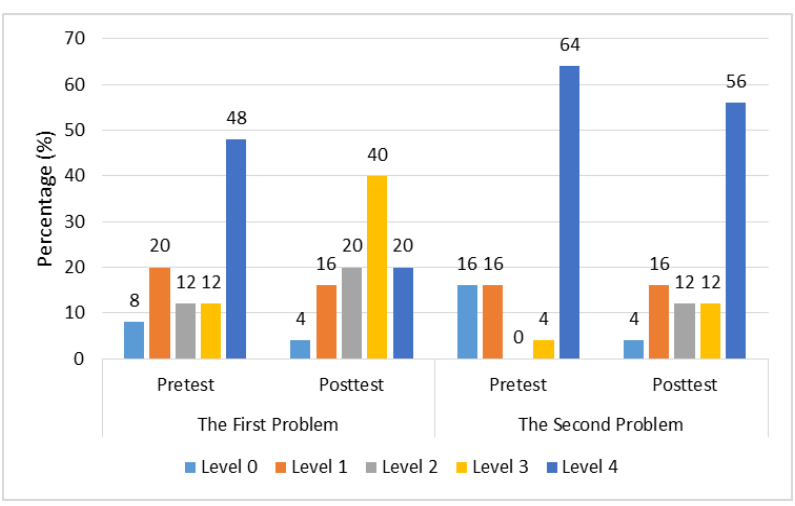

Fig. 2: Students' Proportional Reasoning in Pretest and Posttest

Figure 2 shows most of the students categorized as level 4 (ration), it is about half of the students give the ration answer to the first problem and the second problem. However, Figure 2 shows that the percentage of students who categorized as level 4 slightly decreases. The data also shows students more success to answer the second problem than the first problem.

This study also investigated the typical answer of students in the pretest and the posttest. The following paragraph would show the students' proportional reasoning answers. 


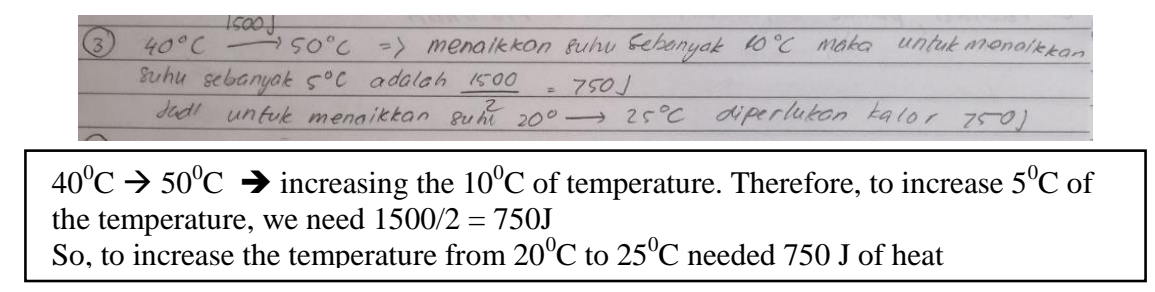

(a)

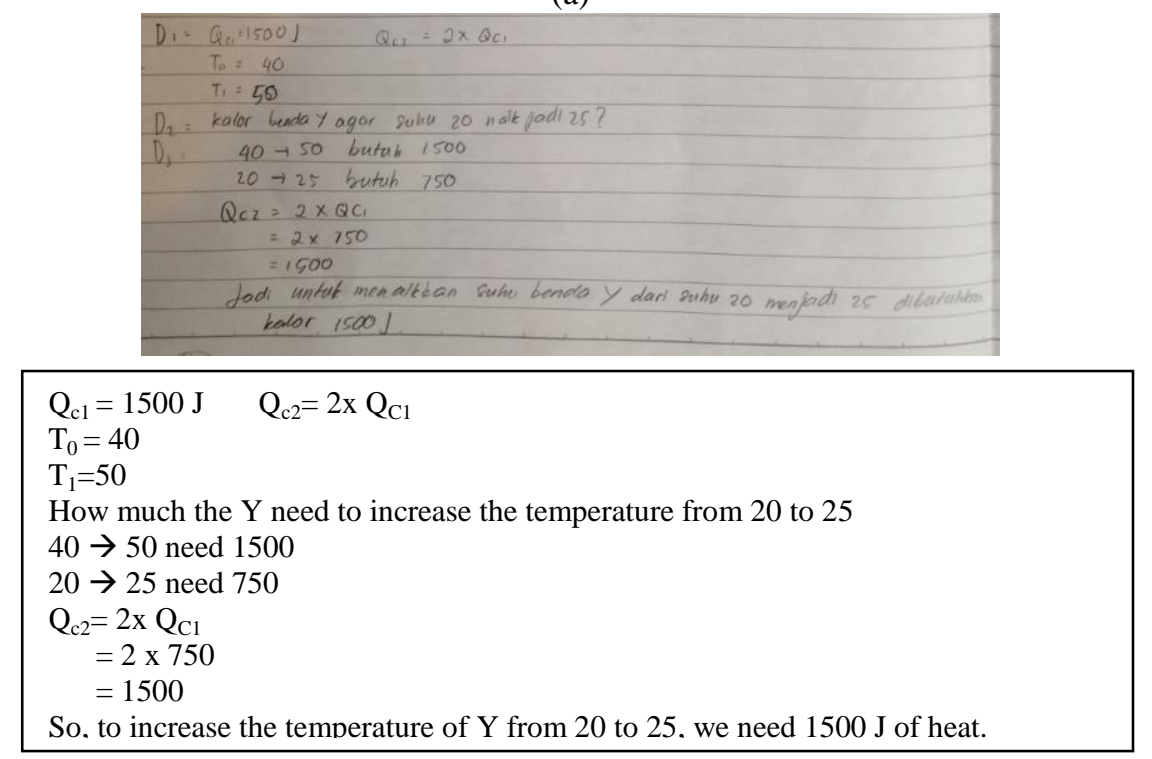

(b)

Fig. 2: The Percentage of Students' Answers in (a) Pretest and (b) Posttest

Figure 2 shows that students only pay attention to one variable that is manipulated, namely a change in temperature of $40^{\circ} \mathrm{C}$ to $50^{\circ} \mathrm{C}$. Students ignore the difference in the heat capacity shown in the problem. There were some students who gave this typical answer. At the post-test, the student still did not give the right answer. Students have considered the differences in the heat capacity of the two objects but are still wrong because it should be the heating capacity of object $\mathrm{X}$ which is twice that of object $\mathrm{Y}$ rather than vice versa.

The interview result showed that students used the proportional strategy that students learned. A student confirmed that: "Actually, I forgot the formula, but I remember the strategy to solve the problem by the proportional way". This interview pieces imply that STEM-based phenomenon learning has to provide an explanation about how to reason by proportional reasoning.

In the second question, most of the students have the correct answer. Students used proportional reasoning correctly. There were only a few students who guess guessed or used a settlement strategy to answer the question.

\section{Discussion}

The results of this study showed that there was no statistically significant difference in students' proportional reasoning after taught by STEM-based phenomenon learning. Despite there was a decrease of students who categorized as level 4 (ration), the percentage of students who categorized as level 4 was relatively high. In particular, the qualitative analysis documented that the students only concern the proportion of one variable that changes and does not pay attention to the changes of another variable.

This result of this study is in line with the results of Ding's [22] study who confirmed that senior high school students showed an earlier increase in proportional reasoning patterns compared to other patterns of reasoning. Factors that also have the potential to be the cause of the high proportional reasoning scores were that the proportional reasoning problem was more mathematical. Novice students tend to start solving problems by 
modifying mathematical equations but do not understand the concept [23]. This allows students to apply physical equations in a nuanced phenomenon but sometimes has difficulty in analyzing why the phenomena occur. Students have difficulty in completing conceptual problems completely [24].

The study identified that the STEM-based phenomenon learning has no influence on students' proportional reasoning. This result may support the reasoning as domain-general. Ding [12] study found that the variables such as university tier, major, and types institution have not affected the students' reasoning. This current study also documented that students only focus on one variable. They were not considered the whole factor that influences the phenomena. This results in line with Woolley et al. [24] study, they revealed that students always confuse to make a proportion of variables.

There was some limitation in this study. The first, the participant involved in this study was limited. Therefore, the generalization of the results was also poor. However, the limited participant provided a chance to observe the students' reasoning skills individually. The second, although the teaching plan was implemented, some students still did not follow the instructional stage. Students with low achievement experienced difficulties to follow the instruction process. The next study should more concerned with the students with low achievements.

\section{Conclusion}

Our main finding revealed that there was no statistically significant difference in students' proportional reasoning after taught by STEM-based phenomenon learning. Most of the students categorized as ration level (level 4). Nevertheless, there was a decrease in students' percentage in level 4. Students' answers indicated that students only concern about the proportion of one variable that changes and does not pay attention to the changes of another variable. The students also indicated to answer the question by inverse proportions. Therefore, the teacher needs to elaborate on another alternative instruction to improve students' proportional reasoning. Further research could be conducted by providing the proportional reasoning strategy in the classroom implicitly. Implementing the STEM-based phenomenon learning in different ages of students could also capture a wide result of STEM-based phenomenon learning and students' proportional reasoning skills.

\section{Acknowledgments}

This research is supported by Lembaga Pengelola Dana Pendidikan (LPDP) of the Republic of Indonesia. The authors also gratefully acknowledge the helpful comments and suggestions of the reviewers, which have improved the presentation.

\section{References}

[1] A. Hilton, G. Hilton, S. Dole, and M. Goos, "Promoting middle school students' proportional reasoning skills through an ongoing professional development programme for teachers," Educ. Stud. Math., vol. 92, no. 2, pp. 193-219, Jun. 2016, doi: 10.1007/s10649-016-9694-7.

[2] National Research Council (U.S.), Ed., A framework for K-12 science education: practices, crosscutting concepts, and core ideas. Washington, D.C: The National Academies Press, 2012.

[3] R. E. Brown, T. Weiland, and C. H. Orrill, "Mathematics Teachers' Use of Knowledge Resources When Identifying Proportional Reasoning Situations," Int. J. Sci. Math. Educ., Aug. 2019, doi: 10.1007/s10763-019-10006-3.

[4] A. Hilton and G. Hilton, "Proportional reasoning: An essential component of scientific understanding," Teach. Sci., vol. 20, no. 4, pp. 32-42, 2016.

[5] A. H. Akatugba and J. Wallace, "Sociocultural influences on physics students' use of proportional reasoning in a nonwestern country," J. Res. Sci. Teach., vol. 36, no. 3, pp. 305-320, 1999, doi: https://doi.org/10.1002/(SICI)10982736(199903)36:3<305::AID-TEA5>3.0.CO;2-1.

[6] A. H. Akatugba and J. Wallace, "An Integrative Perspective on Students' Proportional Reasoning in High School Physics in a West African Context," Int. J. Sci. Educ., vol. 31, no. 11, pp. 1473-1493, Jul. 2009, doi: 10.1080/09500690802101968.

[7] Ü. B. Cebesoy and B. Yeniterzi, "7th Grade Students' Mathematical Difficulties in Force and Motion Unit," Turk. J. Educ., vol. 5, no. 1, p. 18, Mar. 2016, doi: 10.19128/turje.51242. 
[8] B. Bentley and G. C. R. Yates, "Facilitating proportional reasoning through worked examples: Two classroom-based experiments," Cogent Educ., vol. 4, no. 1, Mar. 2017, doi: 10.1080/2331186X.2017.1297213.

[9] I. Dubovi, S. T. Levy, and E. Dagan, "Situated Simulation-Based Learning Environment to Improve Proportional Reasoning in Nursing Students," Int. J. Sci. Math. Educ., vol. 16, no. 8, pp. 1521-1539, Nov. 2018, doi: 10.1007/s10763-017-9842-2.

[10] N. Erlina, E. Susantini, W. Wasis, I. Wicaksono, and P. Pandiangan, "The Effectiveness of Evidence-Based Reasoning in Inquiry-Based Physics Teaching to Increase Students' Scientific Reasoning," J. Balt. Sci. Educ., vol. 17, no. 6, pp. 972-985, Dec. 2018, doi: 10.33225/jbse/18.17.972.

[11] J. L. Jensen, S. Neeley, J. B. Hatch, and T. Piorczynski, "Learning Scientific Reasoning Skills May Be Key to Retention in Science, Technology, Engineering, and Mathematics," J. Coll. Stud. Retent. Res. Theory Pract., vol. 19, no. 2, pp. 126-144, Aug. 2017, doi: 10.1177/1521025115611616.

[12] L. Ding, X. Wei, and X. Liu, "Variations in University Students' Scientific Reasoning Skills Across Majors, Years, and Types of Institutions," Res. Sci. Educ., vol. 46, no. 5, pp. 613-632, Oct. 2016, doi: 10.1007/s11165-015-9473-y.

[13] S.-C. Fan and K.-C. Yu, "How an integrative STEM curriculum can benefit students in engineering design practices," Int. J. Technol. Des. Educ., vol. 27, no. 1, pp. 107-129, Mar. 2017, doi: 10.1007/s10798-015-9328-x.

[14] S. J. Lou, Y. H. Liu, R. C. Shih, and K. H. Tseng, "The senior high school students' learning behavioral model of STEM in PBL," Int. J. Technol. Des. Educ., vol. 21, no. 2, pp. 161-183, May 2011, doi: 10.1007/s10798-010-9112-x.

[15] N. J. Kim, B. R. Belland, and A. E. Walker, "Effectiveness of Computer-Based Scaffolding in the Context of ProblemBased Learning for Stem Education: Bayesian Meta-analysis," Educ. Psychol. Rev., vol. 30, no. 2, pp. 397-429, Jun. 2018, doi: 10.1007/s10648-017-9419-1.

[16] K.-H. Tseng, C.-C. Chang, S.-J. Lou, and W.-P. Chen, "Attitudes towards science, technology, engineering and mathematics (STEM) in a project-based learning (PjBL) environment," Int. J. Technol. Des. Educ., vol. 23, no. 1, pp. 87-102, Feb. 2013, doi: 10.1007/s10798-011-9160-x.

[17] L. Yuliati, Parno, F. Yogismawati, and I. K. Nisa, "Building Scientific Literacy and Concept Achievement of Physics through Inquiry-Based Learning for STEM Education," J. Phys. Conf. Ser., vol. 1097, p. 012022, Sep. 2018, doi: 10.1088/1742-6596/1097/1/012022.

[18] P. Mattila and P. Silander, How to Create The Future: Revolutionary Thinking and Design from Finland. Oulu: University of Oulu Center for Internet Excellence, 2015.

[19] A. E. Lawson, "Deductive reasoning, brain maturation, and science concept acquisition: Are they linked?," J. Res. Sci. Teach., vol. 30, no. 9, pp. 1029-1051, Nov. 1993, doi: 10.1002/tea.3660300904.

[20] J. W. Creswell and V. L. P. Clark, Designing and conducting mixed methods research, Third Edition. Los Angeles: SAGE, 2018.

[21] R. Karplus, H. Adi, and A. E. Lawson, "Intellectual Development Beyond Elementary School VIII: Proportional, Probabilistic, and Correlational Reasoning," Sch. Sci. Math., vol. 80, no. 8, pp. 673-683, Dec. 1980, doi: 10.1111/j.1949-8594.1980.tb09964.x.

[22] L. Ding, "Progression Trend of Scientific Reasoning from Elementary School to University: a Large-Scale CrossGrade Survey Among Chinese Students," Int. J. Sci. Math. Educ., vol. 16, no. 8, pp. 1479-1498, Nov. 2018, doi: 10.1007/s10763-017-9844-0.

[23] E. Kuo, M. M. Hull, A. Gupta, and A. Elby, "How students blend conceptual and formal mathematical reasoning in solving physics problems: Conceptual and Formal Mathematical Reasoning," Sci. Educ., vol. 97, no. 1, pp. 32-57, Jan. 2013, doi: 10.1002/sce.21043.

[24] J. S. Woolley et al., "Undergraduate students demonstrate common false scientific reasoning strategies," Think. Ski. Creat., vol. 27, pp. 101-113, Mar. 2018, doi: 10.1016/j.tsc.2017.12.004. 